https://doi.org/10.48009/1_iis_2010_547-552

\title{
A TECHNOLOGICAL INFRASTRUCTURE DEVELOPMENT ASSESSMENT TO ENABLE A KNOWLEDGE SOCIETY INTO A SMART CITY
}

Elías J. López Padilla, Turabo University, elopez@insolpr.com

Eulalia Márquez Martínez, Turabo University, emarquez@suagm.edu

\begin{abstract}
This paper analyses the actual Telecommunications Infrastructure in the Municipality of Caguas, Puerto Rico in order to be able to make some recommendations for them to have the proper infrastructure on their effort to become a Smart City. It is part of a wider project, Smart Cities: Building its human and informational infrastructure for sustainable innovation and knowledge management Group. Late Caguas Mayor, Mr. William Miranda Marin (deceased on June, 2010), was very interested, made a big effort and invested a great amount of time and money in leading his Municipality to became one of the most technically advanced en Puerto Rico. We made an intensive research on other Smart Cities (SC) implementations, in order to compare them to what Caguas, Puerto Rico has and what is needed for them to accomplish this goal.
\end{abstract}

Keywords: Smart Cities, Knowledge Management, Sustainability

\section{INTRODUCTION}

Information gathered through an explorative method, gave the investigator all the specifics to prepare these recommendations to convert Caguas City into a Smart City or to enhance its current state to become a better and more efficient Smart City. Interviews with City Agency officials, especially with the Director of Information Technology, in charge of all Technical implementations and operations, where of great help in determining the actual status of the City and their growth requirements.

Technological information was also gathered from different sources in the Caguas Municipality, in order to determine the need for improvement, and to be able to recommend the proper enhancements to their infrastructure. Information gathered about the applications in use by Caguas Municipality main and branch offices, helped the investigator in determining if the appropriate tools where in place for the implementation of a Smart City.

Information gathered from the Internet, was used to support or enhance the findings. Comparisons with other implementations, like the Singapore HIT Case
Study (Chien Earn Lee) helped on determining the current state of Caguas City and also to be able to give a more robust and specific recommendation.

\section{OBJECTIVES AND SCOPE}

One of the primary objectives of this investigation was to obtain information regarding the best way to technologically support an implementation of a Smart City, and at the same time give support to its Society in order to have the knowledge required for this. Other main objective is to make recommendations for all paper forms for collecting to be changed to web forms with access through Intranet.

In the same direction, another objective is to help Caguas Municipality to enhance the methodologies currently used to create a paperless environment within their City. Finally, our goal is to verify the actual development of Caguas City and help to make it a leading digital city in the globally connected world of the 21 st century.

Actually, Caguas City is on its way to become a Smart City and its Mayor is determined to complete this goal. Verifying and researching actual implementations and determining which offices already have the requirements for the change and those that are not ready, would help Caguas Mayor on its vision. Helping Caguas to become a Smart City will consequently help its citizens to be part or constitute a Knowledge Society.

As a University within the Caguas City premises, UT has the moral and sociological responsibility to help Caguas and its Mayor on doing so. We as Doctoral Students from UT will help our institution to accomplish this responsibility by developing this kind of proposal or doing this kind or researches.

\section{CAGUAS CITY ACTUAL STATUS}

Caguas City is actually one of the most advanced cities in Puerto Rico, in terms of technological implementations and its use to give their citizens a better service and to help them become more aware of the benefits of becoming a knowledge society. Their intense technological impulse, include the 
centralization of their main offices and services, a very well implemented network that give services to data, voice and video, and a strategy for supporting all of these implementations.

An example of one of their efforts towards a Smart City is the Network established to communicate all agencies and offices. Figure 1 is one of some of the diagrams provided.
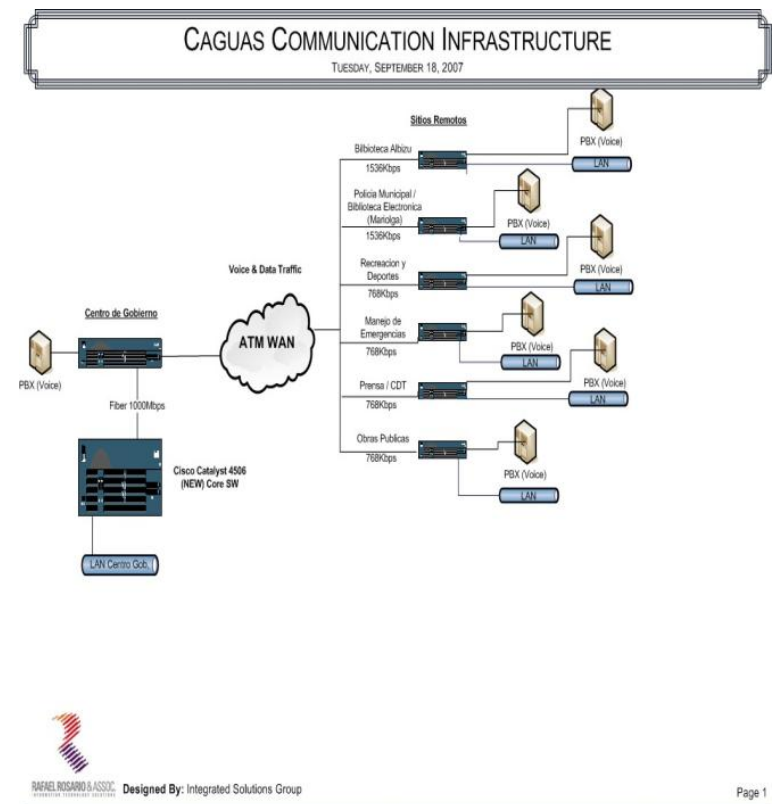

Figure 1 - Caguas Communications Infrastructure (WAN)

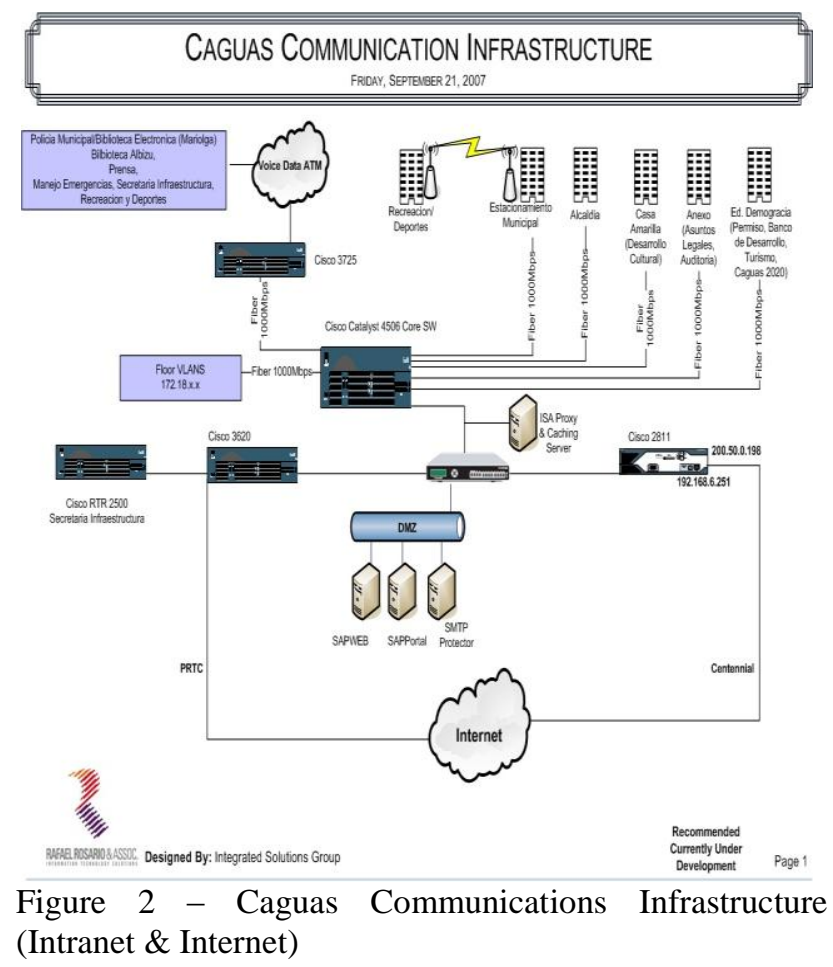

Volume XI, No. 1, 2010
To complement the infrastructure, the administration has established multiple and different connections to their facilities and the Internet, by contracting services from different Service Providers for these connections. They are using the two largest companies that provide these services in PR, PRT (Puerto Rico Telephone) and Centennial.

For telephony, they have all agencies connected to a Central PBX System, providing inter agencies communication through their internal Network; which represents an excellent way of maximizing their resources. They have a hybrid of common phone lines, IP Telephony through the PBX and also IP Telephony on some areas or buildings.

In terms of videoconferencing they use some of Microsoft services and technology, the use e-Learning for trainings, including Applications training like for SAP. Human Resources also use their facilities to give employees seminars and courses on different areas.

In the Public Security area, they have an advanced Virtual Vigilance System, in which they have modernized and improved effectiveness and efficiency in the management of incidents, which are committed by those who violate the safety and public order. This system consist of camera network of high resolution that are strategically located in different areas of the city, which include plazas, school zones, public installations, and other areas. The operation of this system is located in their control center and operates 24 hours $/ 365$ days calendar.

They have an internal Security department, in charge of maintaining all Policies and Procedures in place. This department also monitors all the multiple monitoring devices in place, like Firewalls, IDS (Intrusion Detection Systems), IPS (Intrusion Prevention Systems), AntiSpam and Antivirus equipment, etc.

To support and maintain all Telecommunications and Applications equipment, they use outsourcing and in house staff. To facilitate outsourcing, they have in place standards for cabling (Panduit level 6), communications equipment (CISCO) and Servers (IBM for SAP and DELL for all other Servers).

In addition to its robust Network implementation, Caguas has centralized all of their applications in their Central Facilities, they use SAP for Financial, HR, Contracts Management, etc. Their Web Access Portals, used for Patents payments and for Tourism, E-Mail Applications, Permits Applications and others, are also centralized. This facilitates the administration and maintenance of the equipment required to support all applications.

Actually they have in place individual Servers for each application, but they are moving this technology 
to a Blade implementation and are also evaluating the use of virtual services. They are also considering the option of outsourcing the Servers and Applications environment, meaning having these on a remote facility administered and maintained by an external company or agency.

For Communications equipment and Computers, they are using Lease options, which ensure the maintenance and warranty of all equipment and also provides for continuance of quality, equipment is replaced when obsolete. On specific Projects, especially the ones using Federal specific budgets, they buy the equipments and then establish the proper way to maintain them and to dispose of them when required.

To support all this operation, as stated before, they have some outsourcing services and a minimal specialized technical staff on each area. They also administer the Help Desk services for all agencies, giving first level support and then escalating the requirement as needed, internally or externally. They have one Supervisor and a technical person per area, all other personnel in the IT Department is focused on administrative tasks.

The services provided for the community are also a most for Caguas City; they have agreements with Universities on their City to give Wireless connection to general population, not only for internal students. They have also agreements with establishments, like Gatsby that have a Hot Spot located on their facilities, they provide wireless services on Malls, like Plaza de Palmer, and others. Also, an important strategy is the implementation of WiMax, which by now is being coordinated with local Service Providers to see if they can provide it.

On Libraries through the City, there are computers with Internet connection to the public, providing the public with access to all services provided by the City Government and to Internet Services as well. They have Community Centers with similar types of accesses, where Libraries are not present, or too far. Some of these places are used for Web Conferencing and e-Learning when needed.

Something that has helped very much in Caguas City is that all Technological decisions are made by a committee, conformed by different Agencies Directors or Administrators. This committee has the participation of the Mayor's Assistant, the Director of IT, Human Resources representation and others.

On their future tasks or projects they will be improving their Web Access Portals, enhancing the applications environment and performance. They are also evaluating and will acquire Some Network Monitoring tools for the multiple equipments in place. These equipments will also monitor Servers and their Services, and will concentrate all alarms and reports centrally.

\section{EFFORTS AND STRATEGIES TO BECOME A SMART CITY SUCCESS EXAMPLE}

Singapore: (The e-City: Singapore Internet Case Study, ITU, April 2001\& Singapore HIT Case Study) Advanced and multicultural, the vibrant city-state of Singapore fuses traditional Asian and European cultures with the advantages of modernity and progress. Dazzling skyscrapers and restful parks coexist with the click of mah-jongg tablets and the Muslim call to prayer. Safe and well organized, the city represents a great opportunity to enjoy a range of different Asian cultures.

Modern history cast Singapore as an emporium and nowadays its shops offer the finest goods from all around the world. Chinese, Malaysian, French and American cuisines are served in smart restaurants and busy eating centers, winning the island a world-class reputation for excellence in dining.

Singapore, as an island state with no natural resources, has always lived by its wits. Its inexorable shift from an industrial economy towards an information economy makes it all the more important for Singapore to embrace Information Technology. Defining Singapore's future as an Intelligent Island, the government has embarked on a massive program to build up the necessary infrastructure. But, significantly, the final goal is not just economic growth but an enhancement of the quality of life for all people, making Singapore not just a smart city but a quality city-state.

Tshwane: On the ICF Immersion Lab seminar on Smart City developments in Asia, Mr. Charles Kuun who is responsible for the Tshwane Digital Hub, a Broadband Roll-out Program for the City of Tshwane gave an overview of the ingredients of Tshwane becoming a Smart City. The City of Tshwane is the city of governance with all national government departments' headquarters. The city has 4 universities, University of Pretoria, Tshwane University of Technology, University of South Africa and MEDUNSA.

Seven of the eight government statutory councils (such as CSIR, HSRC, ARC, SABS) are based in the City of Tshwane. The city is also host to two of the 
successful Blue IQ projects; The Innovation Hub and the Automotive Supplier Park. The city also has a 'fiber-optic network' infrastructure that will be conducive for rolling out broadband to citizens, businesses and government facilities.

New York: (Who We Are, What We Do - New York City, David A. Peterson, Governor \& Melodie Mayberry-Stewart, Ph.D. CIO)

A real effort to become a Smart City or to convert their citizens, through City Services in a Knowledge Society is what David A. Paterson, Governor of NY, is accomplishing with their CIO/OFT. New York State Chief Information Officer (CIO)/New York State Office for Technology (OFT) have embarked on a comprehensive and historic effort to draft a new, New York State Enterprise IT Strategic Plan. For the first time ever, the plan will include input from all stakeholders concerned with the procurement of technology, the implementation of IT systems, and the delivery of e-government services. Included in the planning are state agencies and their commissioners, local governments, the executive chamber and technology companies.

This inclusive and all-encompassing approach will ensure the IT strategic direction of the state reflects the real business needs of the state agencies. "We intend for this to be the most inclusive IT strategic plan New York State has ever done," Dr. Melodie Mayberry-Stewart, NYS Chief Information Officer and Director of the Office for Technology said. "The more participation we have from the state enterprise, the more relevant, sustainable, and credible our plan will be. I have no doubt this can become a best practice for others to emulate." To collect input for the plan, CIO/OFT is meeting with state agencies through the CIO Council Action Teams, and will meet separately with agency commissioners in small focus groups.

City of Cape Town: (Nirvesh Sooful, Interim Manager: Information Technology, City of Cape Town)

The city government of Cape Town is planning to build a partnership with its entire people to make Cape Town a world-class city in which the quality of every citizen's life steadily improves. Mindful of that which gives their city its unique character, they commit their selves to nurturing Cape Town's spectacular natural beauty, to preserving its rich heritage and to enriching its exciting mix of dynamic cultures.

In partnership with all their people they commit themselves to fight crime, combat HIV/AIDS, promote job creation through a special focus on tourism, and provide every Cape Townian with free basic services. Their vision is of a safe city that is clean, attractive to investors, welcoming to visitors and underpinned by a vibrant, growing economy. Their vision is of a well-run, democratic city that is accountable to the people of Cape Town, corruption free, transparent in all its activities and prudent in the management of its finances.

Their vision is of a city in which no one is left behind, where everyone has access to opportunity and everyone is guaranteed basic life-line services. Their vision is of an open, tolerant city in which every resident feels at home. Their vision is of a smart city populated by informed people, connected to the world and each other by the technology of the information age. Their vision is of a city filled with concerned citizens, in which every person takes responsibility for the good order, high standards and upkeep of the city and its environment.

They commit themselves to a focus on the citizen as customer, to be responsive to the needs of the people and to efficiently deliver affordable services to all. Together with the people of Cape Town, the government will strive to make their city the best place to live, to work, to invest and to visit in all of South Africa.

\section{RECOMMENDATIONS}

After reviewing the specifics of what Caguas City has in place and all of the efforts and success stories of the Cities that had became a Smart City, there are some additional efforts that can be made by Caguas to obtain their goal, become a Smart City. Looking at Caguas Internet penetration, they have a $27 \%$ of Internet access penetration; wish is a very good percentage for a small City (Caguas City Internet Portal). When looking at Latin America Internet Usage, Puerto Rico has a 23\% of Internet Penetration (Internet World Stats), so Caguas has one of the most intense Internet access in the Island. Following is a table, stating the different Latin American Countries or Cities Internet penetration information (Internet World Stats). 
Table 1. Latin American Internet Usage

\begin{tabular}{|c|c|c|c|c|c|}
\hline \multicolumn{6}{|c|}{ Latin American Internet Usage } \\
\hline $\begin{array}{c}\text { LATIN AMERICA } \\
\text { COUNTRIES / REGIONS }\end{array}$ & $\begin{array}{l}\text { Population } \\
\text { (Est. 2007) }\end{array}$ & $\begin{array}{l}\text { Internet Users, } \\
\text { Latest Data }\end{array}$ & $\begin{array}{l}\text { \% Population } \\
\text { (Penetration) }\end{array}$ & $\begin{array}{l}\text { \% Users } \\
\text { in Table }\end{array}$ & $\begin{array}{l}\text { Use Growth } \\
\text { (2000-2007) }\end{array}$ \\
\hline Argentina & $40,301,927$ & $16,000,000$ & $39.7 \%$ & $13.0 \%$ & $540.0 \%$ \\
\hline Bolivia & $9,199,152$ & 580,000 & $6.4 \%$ & $0.5 \%$ & $383.3 \%$ \\
\hline Brazil & $190,010,647$ & $42,600,000$ & $22.4 \%$ & $34.7 \%$ & $752.0 \%$ \\
\hline Chile & $16,284,741$ & $7,035,000$ & $43.2 \%$ & $5.7 \%$ & $300.3 \%$ \\
\hline Colombia & $44,379,598$ & $10,097,000$ & $22.8 \%$ & $8.2 \%$ & $1,050.0 \%$ \\
\hline Costa Rica & $4,133,884$ & $1,214,400$ & $29.4 \%$ & $1.0 \%$ & $385.8 \%$ \\
\hline Cuba & $11,394,043$ & 240,000 & $2.1 \%$ & $0.2 \%$ & $300.0 \%$ \\
\hline Dominican Republic & $9,365,818$ & $2,100,000$ & $224 \%$ & $1.7 \%$ & $3,718.2 \%$ \\
\hline Ecuador & $13,75,680$ & $1,549,000$ & $11.3 \%$ & $1.3 \%$ & $700.6 \%$ \\
\hline El Salvador & $6,948,073$ & 700,000 & $10.1 \%$ & $0.6 \%$ & $1,650.0 \%$ \\
\hline Guatemala & $12,78,111$ & $1,320,000$ & $10.4 \%$ & $1.1 \%$ & $1,930.8 \%$ \\
\hline Honduras & $7,488,763$ & 344,100 & $4.6 \%$ & $0.3 \%$ & $700.3 \%$ \\
\hline Mexico & $108,700,891$ & $23,700,000$ & $21.8 \%$ & $19.3 \%$ & $773.8 \%$ \\
\hline Nicaragua & $5,675,356$ & 155,000 & $27 \%$ & $0.1 \%$ & $210.0 \%$ \\
\hline Panama & $3,242,173$ & 264,316 & $82 \%$ & $0.2 \%$ & $487.4 \%$ \\
\hline Paraguay & $6,699,086$ & 260,000 & $3.9 \%$ & $0.2 \%$ & $1,200.0 \%$ \\
\hline Peru & $28,674,757$ & $7,324,300$ & $25.5 \%$ & $6.0 \%$ & $193.0 \%$ \\
\hline Puerto Rico & $3,944,259$ & 915,600 & $23.2 \%$ & $0.7 \%$ & $357.8 \%$ \\
\hline Uruguay & $3,450,607$ & $1,100,000$ & $31.8 \%$ & $0.9 \%$ & $197.3 \%$ \\
\hline Venezuela & $20,023,528$ & $5,297,798$ & $20.4 \%$ & $4.3 \%$ & $457.7 \%$ \\
\hline TOTAL & $552,296,094$ & $122,796,514$ & $222 \%$ & $100.0 \%$ & $590.1 \%$ \\
\hline
\end{tabular}

Considering all efforts and strategies already in place or in the process on implementation considered, there are still some areas that Caguas municipality could improve, following are some recommendations on these areas:

$>$ Quality improvement on the infrastructure is needed; specific details should be discussed with technical specialists on this matter. Fiber Optic connections to main agencies buildings, between them and to other organizations could be a good start to this improvement.

$>$ Actual bandwidth between agencies and/or City buildings, and their connection to Internet, should be enhanced to at least a 3 to $5 \mathrm{Mbps}$ in the next three to five years implementations.

$>$ The Mayor has a Strategic Plan, it should be revised to include a specific Plan for technical developments and implementations, Policies reviews, and plan for immediate, medium and long term plans and strategies.

$>$ Electronic work flow should be the prime vehicle for transmission of data in Caguas City agencies and or offices.

$>$ The Committee established to evaluate and determine the needs of the City in terms of Technological equipment and resources should be revised. This committee should become what other Cities have established, a
Common Stakeholders Group, including external participants, like Universities, Private Companies and others with the technological and economical resources to help all City developments.

$>$ Require collaboration from the private sector is also important, especially Broadband Operators, Service Providers, Universities, Pharmaceuticals, etc. Caguas have some strategic alliances with some of these today, improvement is vital if they want to succeed and prolonged their continuity of growth and quality in technology implementations. By these collaborations, duplication of efforts and implementations could be reduced, even eliminated, using the common resources of each participant on their technology implementations. Also technology infrastructure duplication could be reduced or eliminated, and a better use for existing individual infrastructures, properly connected, will support their technology needs.

$>$ They have already some services provided to rural areas, a more robust infrastructure should be provided in these areas to provide the quality of services that urban and central citizens have near them.

$>$ Regional expansion is a most, efforts like the INTECO ("Iniciativa Tecnológica Centro Oriental" in Spanish, which means Technology Initiative for Central and Oriental Towns) participation they have is very important. Other municipalities, near the Caguas City, have the empowerment and some of the resources needed to complement their efforts and extend their services.

$>$ Some visionary implementations are already in place, but continuity of these will ensure the success of Caguas in their goal of becoming a Smart City. Examples of some new visionary efforts that can be considered are: Rural and remote health care, enhancement of the security monitoring extending it to rural areas, broadcasting internet TV, E-Work pilots, Enhance Videoconferencing in education, and many more.

\section{CONCLUSION}

Caguas City has the potential of becoming the first real Smart City in Puerto Rico, and become the standard for others to follow. Although other major 
cities are following the same goals, Caguas Mayor has accomplished them more efficiently and in a shorter period of time. Now, what follows is to help their citizens become a knowledge society.

Countries will only succeed in the 21 st century if they have citizens who are creative, adaptable and skilled. People with the proper skills, talents, knowledge and creativity, are the key to future success. Caguas City must prioritize on the provision of opportunities for everyone to learn and to develop their skills and abilities.

Knowledge has value, but so too does knowledge about knowledge. Creating value is about creating new knowledge and capturing its value. More important than physical property is now intellectual property. The minds and ideas of people, rather than traditional tasks in companies, are now essential to growth and prosperity. The emergence of the knowledge society means an ever-increasing demand for a well-educated and skilled workforce across the whole economy.

Advanced microelectronics-based information and communication technologies (ICTs) are at the heart of recent social and economic transformations in both the industrialized and many developing countries. Developing countries are being encouraged to invest in their national information infrastructures so that they can participate in knowledge-based development and experience the predicted social and economic benefits.

The next society will be a knowledge society. Knowledge will be its key resource, and knowledge workers will be the dominant group in its workforce [Peter Drucker, The Next Generation, November 2001] With this words from Mr. Drucker, no more need to be said about knowledge and the importance that it has for any Company, City, Country or Continent to have the people with the skills and abilities to become a knowledge society.

\section{REFERENCES}

1. Building a Smart City through wireless technology, Case Study, Government, Fredericton, New Brunswick's Capital City

2. Caguas, PR City Profile. Caguas, PR Facts, News and Neighborhood Information.

3. Caguas City Internet Portal - Caguas.Com
4. Clearwire Clears $\$ 1.26$ Billion in Funding, By Eric Griffith July 6, 2006

5. Connecting People and Information

6. Charles Riggle, Vice President Bus. Dev., NextNet Wireless rigglec@nextnetwireless.com, www.nextnetwireless.com

7. Developments in the Fields, Software Engineering Professionalism, Standards, and Best Practice http://ict.satw.ch/SPIP/article.php3?id_article $=42$

8. ICF Immersion Lab seminar on Smart City developments in Asia http://www.theinnovationhub.com/NewsBits/vol 6no4/news07.cfm

9. Kansas City, Missouri, Case Study Report U.S. DEPARTMENT OF COMMERCE National Telecommunications \& Information Administration

10. Libraries in Singapore, Bernhard Mittermaier

11. Internet World Stats http://www.internetworldstats.com/stats 10.htm

12. Project Initiatives by Willie Miranda Marin

13. Singapore HIT Case Study Chien Earn Lee, Senior Director, Health Performance Group, Ministry of Health Bee Kwan Lim, Deputy Director, Infocomm Division, Ministry of Health Peter Chin Seng Tan, Assistant Director, eHealth, Infocomm Division, Ministry of Health

14. Who We Are, What We Do - New York City, David A. Peterson, Governor \& Melodie Mayberry-Stewart, Ph.D. CIO

15. Smart City 2020, William J. Mitchell, March 20, 2006 Metropolismag.com

16. The Impact of Virtualization Software on Operating Environments http://www.webbuyersguide.com/bguide/Whitep aper/brief.asp?wpid=ODg4Ng\&src=vmwareccsl $\mathrm{n}$

17. The e-City: Singapore Internet Case Study ITU, April 2001

18. The Next Society, Peter Drucker, Economist, 1 November 2001 http://economist.com/surveys/displayStory.cfm? Story_id=770819

19. The role of standards in the knowledge society http://www.ebst.dk/publikationer/national_stand ardisation_strategy_of_denmark/html/chapter03. htm

20. Transforming local government with an IT enabled strategy - Cape Town's 'smart city' strategy Nirvesh Sooful, Interim Manager: Information Technology, City of Cape Town 